\title{
Prevention of migraine in the pill-free interval of combined oral contraceptives: A double-blind, placebo-controlled pilot study using natural oestrogen supplements
}

\author{
E Anne MacGregor, MB BS, MFF,, Director of Clinical Research, The City of London Migraine Clinic, London, UK, and \\ Departments of Gynaecology and Sexual Health, St Bartholomew's Hospital, London, UK; Allan Hackshaw, MSc, Senior \\ Lecturer in Epidemiology and Medical Statistics, Wolfson Institute of Environmental and Preventive Medicine, Charterhouse \\ Square, London EC1M 6BQ, UK
}

Correspondence: Dr E A MacGregor, Director of Clinical Research, The City of London Migraine Clinic, 22 Charterhouse Square, London EC1M 6DX, UK. Tel: (44) 7251 3322.Email: eamacg@aol.com

(Accepted 24 $4^{\text {th }}$ June 2001)

The Journal of Family Planning and Reproductive Health Care 2002: 28(1): 27-31

\begin{abstract}
Context. Migraine in the pill-free interval of combined oral contraceptives is reported by many women, but there is little published information on possible mechanisms and treatments.

Objective. To determine whether the use of natural oestrogen patches affected the occurrence and severity of migraine during the pill-free interval.

Design. A double-blind, placebo-controlled, randomised, crossover study.

Setting. The City of London Migraine Clinic.

Participants. Fourteen women with migraine during the pill-free interval.

Interventions. $50 \mu \mathrm{g}$ oestradiol patches (Evorel ${ }^{\mathrm{TM}}$ ) used during the pill-free interval for two cycles versus placebo for two cycles (total four cycles).

Main outcome measures. Number of pill-free intervals (zero, one or two) during which migraine occurred; number of days of migraine; severity of migraine; number of days of migraine accompanied by nausea, vomiting and/or photophobia.

Results. Complete data were available for 12 women and for two cycles for one woman. Use of $50 \mu \mathrm{g}$ oestrogen patches during the pill-free interval showed a trend towards reducing the frequency and severity of migraine.

Discussion. These results were not as good as expected. However, we had originally aimed for 20 eligible women to participate in the trial, but only 14 were recruited and only 12 completed the study with full data for analysis.

Conclusion. The results of this pilot study suggest that use of $50 \mu \mathrm{g}$ oestrogen patches during the pill-free interval may reduce the frequency and severity of migraine at that time. This study should be repeated with larger numbers of women and a higher dose of oestrogen.
\end{abstract}

\section{Key message points}

- Migraine without aura often occurs in the pill-free interval of combined oral contraceptives.

- The drop in the level of oestrogen is the most likely trigger.

- $50 \mu \mathrm{g}$ oestrogen patches used during the pill-free interval may reduce the frequency and severity of migraine.

- $100 \mu \mathrm{g}$ oestrogen patches are more likely to be effective but this needs to be confirmed in further studies.
Headache is a common side effect of combined oral contraceptive (COC) use, with initial exacerbation in the early cycles of use followed by resolution with continued use. ${ }^{1}$ The frequency of headache may depend on the type of progestogen and the dose of oestrogen used. Studies of COCs containing levonorgestrel, a second-generation progestogen, note headache in approximately $10 \%$ of all cycles. $^{2}$ In contrast, COCs containing third-generation progestogens appear to be less associated with headache. A review of studies using a COC containing $30 \mu \mathrm{g}$ ethinyloestradiol and $150 \mu \mathrm{g}$ desogestrel found headache to affect only $5 \%$ of women during the sixth cycle. ${ }^{3}$ Lower doses of ethinyloestradiol also appear to be associated with less reported headache: a review of studies using only $20 \mu \mathrm{g}$ ethinyloestradiol and $150 \mu \mathrm{g}$ desogestrel noted headache incidence of less than $2 \%$ by the sixth cycle. ${ }^{4}$

The effect of COCs on migraine is extremely variable. It is important to note that in a significant proportion of women, migraine improves and many report no change in migraine frequency or severity. However, onset of migraine has been reported as being ten times more common in women starting the oral contraceptive pill compared to a control population. ${ }^{5}$ Unfortunately, the true effect of oral contraceptives on migraine is uncertain, as few controlled studies have been undertaken. One pattern that has emerged is the tendency for attacks to occur during the pill-free interval of the cycle. ${ }^{6-11}$

\section{Mechanism of migraine during the pill-free interval}

The mechanism for attacks during the pill-free interval is uncertain, but circumstantial evidence suggests a link with oestrogen withdrawal. This mechanism is similar to that for 'menstrual' migraine, defined as migraine attacks occurring exclusively between Day $1 \pm 2$ of the menstrual cycle in women not taking hormones for contraception or hormone replacement therapy (HRT). ${ }^{12}$ Studies by Somerville show that attacks occurring at this stage of the menstrual cycle appear to be associated with naturally falling levels of oestrogen in the late luteal phase of the cycle. ${ }^{13,14}$ Several other studies support Somerville's oestrogen withdrawal theory. Epstein et al. noted that the extent of decline from peak to trough oestrogen was greater in all the migraine subjects than in the women in the control group who did not have migraine. ${ }^{15}$ They concluded that variation in hormonal activity may be a potentially relevant factor in all women 
with migraine, with factors additional to the hormonal environment being responsible for the difference between subgroups of women with migraine linked or not linked to menstruation. Lichten et al. studied postmenopausal women challenged with oestrogen confirming that, in some of these women, a drop in serum oestrogen could precipitate migraine, and that a period of oestrogen priming was a necessary prerequisite. ${ }^{16}$

If oestrogen withdrawal is a mechanism for menstrual migraine, it follows that attacks might be prevented using oestrogen supplements. To this end, Somerville successfully treated 'menstrual' migraine using injections of oestradiol valerate. ${ }^{17}$ Other studies supplementing oestrogen perimenstrually with percutaneous gel ${ }^{18,19}$ and transdermal patches have also controlled 'menstrual' migraine. ${ }^{20-22}$

Only one published study has specifically attempted to treat headaches (not distinguished from migraine) in the pill-free interval of combined oral contraceptives, using oral ethinyloestradiol. ${ }^{23}$ Improvement was seen in 34 of 50 women given 5-20 $\mu \mathrm{g}$ ethinyloestradiol during the pill-free interval, but there was no response to placebo. No comment was made on whether one dose was more effective than any other dose. However, the study is subject to a number of criticisms, not least because it was neither randomised nor double-blinded.

Given that migraine in the pill-free interval is a wellrecognised clinical problem, it is surprising that more research has not been undertaken to study its prevalence and to identify mechanisms.

\section{Current practice for prevention of migraine in the pill-free interval}

Given the paucity of clinical trial evidence, prevention and management of migraine in the pill-free interval has been essentially based on theory.

If oestrogen withdrawal is the mechanism for migraine arising in the pill-free interval, minimising the decline in oestrogen during the pill-free interval should prevent attacks.

Such attacks may also be resolved by altering the ratio of oestrogen to progestogen, ${ }^{9}$ more commonly by bicycling or tricycling the pill (taking two or three packets consecutively before breaking for a pill-free interval $)^{24}$ or, based on empirical evidence, by using percutaneous oestrogens in the pill-free interval. $\mathrm{Bi}$ - or tricycling the pill may be the simplest method, reducing the number of pill-free intervals, and thus the number of migraine attacks, from 13 to five per year. However, this regimen may not be without risk. Results from one study of eight women taking high-dose second-generation combined contraceptives suggested that the unfavourable metabolic changes that can develop during pill-taking appear to reverse during the pill-free interval. ${ }^{25}$ Although the adverse metabolic changes during pill-taking are markedly reduced with modern low-dose COCs, any potential benefits gained by monthly 'breaks' would be lost if the number of pill-free intervals is reduced. This may not be relevant for the majority of pill users, but may be important for 'high-risk' women if studies of COC users suggesting synergy of risks for thrombotic events, which include migraine, are correct. ${ }^{26-28}$

Using natural oestrogen such as oestradiol during the pill-free interval could, if the oestrogen withdrawal theory is correct, prevent attacks of migraine at this stage of the pill cycle. Such a regime could be preferable to bi- or tricycling the pill by virtue of the possible reduced effects of physiological doses of natural oestrogens versus high-dose synthetic contraceptive oestrogens on metabolic and thrombotic parameters, although the true benefit is unclear. ${ }^{29}$ Withdrawal bleeds would still occur, reported by some women to be a reassuring sign that they are not pregnant - despite providing little reassurance to the clinician. A clinical trial is necessary to find out whether oestradiol supplements would be effective in this manner. However, knowing the problems of recruitment in clinical trials, and because no previous studies have been undertaken using oestradiol in the pill-free interval, it was felt that a pilot study would be appropriate in the first instance.

The study was designed to test feasibility and methodology as a forerunner to a larger and more conclusive study, if the results suggested further work to be worthwhile.

\section{Aim}

The aim of this study was to determine whether the use of natural oestrogen patches during the pill-free interval affected the occurrence of migraine headache and associated symptoms.

\section{Method}

The study protocol was approved by the East London and City Research Ethics Committee. Women who fulfilled the entry criteria were invited to participate in a double-blind, placebo-controlled, randomised, crossover study in which each woman was given oestrogen patches (Evorel ${ }^{\mathrm{TM}} 50 \mu \mathrm{g}$ ) or matching placebo, each to be used during the pill-free interval of four pill cycles allocated at random (two cycles using oestrogen, two using placebo). This enabled a withinperson analysis of the data to be possible.

Most patients were recruited from outpatient clinics at the City of London Migraine Clinic and at Bart's Sexual Health Centre. A few were also recruited following advertisements placed in the waiting room at the Margaret Pyke Family Planning Centre and in other local family planning clinics. As recruitment was poor, advertisements were also placed in local newspapers but, despite a good response, few suitable subjects were identified. All women were seen at the City of London Migraine Clinic. In order to fulfill the entry criteria, they must have been aged over 18 years and suffering from recurrent attacks of migraine without aura during the pill-free interval, fulfilling the criteria proposed by the International Headache Society. ${ }^{30}$ They must have had migraine without aura for at least 1 year and have been using the same COCs for at least 6 months prior to entering the study. There must have been no contraindications to their continuing use of COCs. All women entered gave informed consent and were free to withdraw at any stage of the study for any reason.

A full medical and headache history was taken from all women, who were then given a neurological and general physical examination. All information was recorded on the case report form. Women were then randomly allocated to receive oestrogen or placebo patches that were to be used during the pill-free interval. Two patches were provided for each cycle: the first was to be used on the evening of the last day of the pill cycle, replaced with the second patch on the morning of the fourth day of the pill-free interval, removed on the first day of the next pill cycle. Diary cards were provided which highlighted the correct time for patch changes. Women were asked to use the diary cards to record any headache or migraine occurring at any time during the 4-month study period, using a verbal rating scale for severity. Associated symptoms of nausea, vomiting and 
photophobia were also recorded, as was use of medication for acute treatment. Women were seen at the City of London Migraine Clinic after the first two cycles to check blood pressure and to monitor adverse events, and at the end of the fourth cycle for a third and final assessment. Trial medication was issued for two cycles at the first and second visits.

The following outcomes were assessed during the two pill-free intervals for each treatment and placebo regimen:

- The number of pill-free intervals (zero, one or two) during which at least one migraine occurred.

- The number of days during which a migraine occurred (0 to 14$)$ over the 2 weeks.

- The number of migraines which were considered to be mild, moderate or severe.

- The number of days of migraine (0 to 14$)$ over 2 weeks which were accompanied by nausea.

- The number of days of migraine (0 to 14 ) over 2 weeks which were accompanied by vomiting.

- The number of days of migraine (0 to 14 ) over 2 weeks which were accompanied by photophobia.

\section{Sample size calculation and statistical methods}

A crossover trial of 20 patients would have over $90 \%$ power to show a difference of $50 \%$ reduction in the outcomes assessed.

Non-parametric tests (Wilcoxon one-sample test) were used to compare the median within-person differences and $t$-tests for comparing the mean.

\section{Results}

We were unable to meet our recruitment target of 20 patients (for reasons, see Discussion). Fourteen women, median age 33 years (range 24-42), with a median onset of migraine without aura at age 19 years (range 7-41) were recruited over a 2-year period. The brand names of COCs taken by each woman are listed in Table 1. Eight women took third-generation COCs (all monophasic) and six took second-generation COCs (four monophasic and two triphasic).

Thirteen women had taken their current COC for at least 6 months, and one woman had taken hers for 3 months. Attacks of migraine were typically reported as starting on the second or third day of the pill-free interval.

Of the 14 women, one withdrew consent before starting treatment. The analyses are therefore based on 13 women: 12 who completed the study and had full data (four cycles in total) and one who withdrew after two cycles.

Only two adverse events were reported that could be
Table 1 Brand of COC used by each patient

\begin{tabular}{llll}
\hline $\begin{array}{l}\text { Patient } \\
\text { number }\end{array}$ & $\begin{array}{l}\text { COC } \\
\text { brand name }\end{array}$ & $\begin{array}{l}\text { Patient } \\
\text { number }\end{array}$ & $\begin{array}{l}\text { COC } \\
\text { brand name }\end{array}$ \\
\hline 01 & Femodene & 08 & Dianette \\
02 & Dianette & 09 & Mercilon \\
03 & Mercilon & 10 & Marvelon \\
04 & Cilest & 11 & Microgynon \\
05 & Trinovum & 12 & Microgynon \\
06 & Logynon & 13 & Mercilon \\
07 & Microgynon & 14 & Microgynon \\
\hline
\end{tabular}

attributable to the study medication. One patient reported no withdrawal bleed and no headaches or migraine in the two pill-free intervals using oestrogen patches. On Day 5 of each pill-free interval in which she used placebo, she experienced a withdrawal bleed and associated migraine attack.

Another patient experienced withdrawal bleeds starting on Day 4 of the pill-free interval for both placebo cycles and on Days 3 and 4 of the pill-free interval in the two oestrogen cycles. She reported that the withdrawal bleed was much lighter than usual during the two oestrogen cycles, but migraine occurred and was unchanged from usual.

The only other adverse event, reported by a third patient, was early bleeding on Days 19 or 20 of the pill cycle during every cycle in the study and preceded use of active study medication.

There was no evidence to suggest that women had fewer pill-free intervals with migraine after using $50 \mu \mathrm{g}$ oestrogen patches compared to placebo. Ten of the 13 women had the same number of weeks with migraine whether they were using oestrogen or not, two women had fewer weeks and one woman had more weeks (Table 2).

With respect to the number of days where the women had migraine during the pill-free interval, there was a suggestion that when the women were using $50 \mu \mathrm{g}$ oestrogen patches, they had fewer days of migraine than when they were using placebo [median difference -1 day, $95 \%$ confidence interval $(\mathrm{CI})-3.0,2.8]$, but the results were not statistically significantly different $(\mathrm{p}=0.68)$ (Table 2$)$.

The frequencies of mild, moderate or severe migraines in women using $50 \mu \mathrm{g}$ oestrogen patches or placebo are shown in Table 3. The overall severity of migraine was assessed using a weighted difference score which suggested that women using oestrogen tended to have less severe migraine but the difference was again not statistically significantly different (median $-1.5,95 \% \mathrm{CI}-6.6,2.8 \mathrm{p}=0.50$ ).

There was a slight indication that women tended to have

Table 2 The number of pill-free weeks when a migraine occurred and the number of days with migraine during each 2-week period when given treatment or placebo

\begin{tabular}{|c|c|c|c|c|c|c|}
\hline \multirow[b]{2}{*}{ Patient number } & \multicolumn{3}{|c|}{ Number of pill-free weeks ( 0 to 2 ) } & \multicolumn{3}{|c|}{ Number of migraines ( 0 to 14 ) } \\
\hline & Oestrogen & Placebo & Difference & Oestrogen & Oestrogen & Difference \\
\hline 1 & 2 & 2 & 0 & 3 & 4 & -1 \\
\hline 2 & 1 & 1 & 0 & 1 & 1 & 0 \\
\hline 3 & 1 & 2 & -1 & 3 & 5 & -2 \\
\hline 4 & 2 & 2 & 0 & 6 & 9 & -3 \\
\hline 5 & 2 & 2 & 0 & 6 & 11 & -5 \\
\hline 6 & 0 & 2 & -2 & 0 & 3 & -3 \\
\hline 7 & 1 & 1 & 0 & 1 & 1 & 0 \\
\hline 8 & 2 & 2 & 0 & 4 & 5 & 1 \\
\hline 9 & 2 & 2 & 0 & 5 & 5 & 0 \\
\hline 10 & 2 & 1 & 1 & 10 & 3 & 7 \\
\hline 11 & 1 & 1 & 0 & 2 & 1 & 1 \\
\hline 12 & 2 & 2 & 0 & 11 & 8 & 3 \\
\hline 13 & 2 & 2 & 0 & 2 & 2 & 0 \\
\hline
\end{tabular}


Table 3 The number of days ( 0 to 14) with migraine according to the severity

\begin{tabular}{|c|c|c|c|c|c|c|c|c|c|c|}
\hline \multirow[b]{3}{*}{$\begin{array}{l}\text { Patient } \\
\text { number }\end{array}$} & \multicolumn{9}{|c|}{ Number of days associated with migraine attacks which were } & \multirow[b]{3}{*}{$\begin{array}{l}\text { Weighted } \\
\text { score }^{\mathrm{a}}\end{array}$} \\
\hline & \multicolumn{3}{|l|}{ Mild } & \multicolumn{3}{|l|}{ Moderate } & \multicolumn{3}{|l|}{ Severe } & \\
\hline & Oestrogen & Placebo & Difference & Oestrogen & Placebo & Difference & Oestrogen & Placebo & Difference & \\
\hline 1 & 1 & 3 & -2 & 1 & 1 & 0 & 1 & 0 & 1 & 1 \\
\hline 2 & 1 & 1 & 0 & 0 & 0 & 0 & 0 & 0 & 0 & 0 \\
\hline 3 & 2 & 4 & -2 & 1 & 1 & 0 & 0 & 0 & 0 & -2 \\
\hline 4 & 0 & 0 & 0 & 1 & 1 & 0 & 5 & 8 & -3 & -9 \\
\hline 5 & 3 & 2 & 1 & 1 & 3 & -2 & 2 & 6 & -4 & -15 \\
\hline 6 & 0 & 1 & -1 & 0 & 0 & 0 & 0 & 2 & -2 & -7 \\
\hline 7 & 1 & 0 & 1 & 0 & 0 & 0 & 0 & 1 & -1 & -2 \\
\hline 8 & 1 & 0 & 1 & 2 & 4 & -2 & 1 & 1 & 0 & -3 \\
\hline 9 & 2 & 2 & 0 & 3 & 2 & 1 & 0 & 1 & -1 & -1 \\
\hline 10 & 4 & 3 & 1 & 1 & 0 & 1 & 5 & 0 & 5 & 18 \\
\hline 11 & 0 & 0 & 0 & 0 & 1 & -1 & 2 & 0 & 2 & 4 \\
\hline 12 & 5 & 2 & 3 & 6 & 6 & 0 & 0 & 0 & 0 & 3 \\
\hline 13 & 0 & 1 & -1 & 2 & 1 & 1 & 0 & 0 & 0 & 1 \\
\hline
\end{tabular}

${ }^{\mathrm{a}} \mathrm{A}$ weighted difference score for each woman was obtained by multiplying the difference in the number of days with mild migraine by a score of 1 , the difference in days with moderate migraines by a score of 2 and the difference in days with severe migraines by a score of 3 . These are summed to yield a total score for each woman.

migraine with nausea when using the patches, though this is only based on six women who experienced nausea at any time. Of these six, five reported more migraines with nausea during the weeks on oestrogen patches and one reported fewer migraines with nausea (Table 4).

Only two women experienced vomiting either using $50 \mu \mathrm{g}$ oestrogen supplements or placebo, one woman had two more episodes with oestrogen and one had two fewer episodes. No further comment could be made on this (Table 4).

There was no evidence to suggest that migraines associated with photophobia were affected by oestrogen use $(\mathrm{p}=0.79)$ (Table 4).

\section{Discussion}

The results of this pilot study suggest that use of $50 \mu \mathrm{g}$ oestrogen patches during the pill-free interval of combined COCs may reduce the frequency and severity of migraine at that time. The results were not as good as we had expected. We had originally aimed for 20 eligible women to participate in the trial but only 14 were recruited and only 12 completed the study with full data for analysis. Also we observed less than a $50 \%$ difference in the outcomes assessed and, together with the smaller than intended sample size, this explains the lack of statistical significance in our results.

The City of London Migraine Clinic is a research centre so all staff were experienced in undertaking clinical trials and diagnosing migraine. However, one of the major problems with the study was recruiting patients, despite the long period available for recruitment. In clinical practice, migraine and headache occurring in the pill-free interval is common. However, as Hamilton put it, 'In any investigation involving human subjects the most difficult part is getting hold of them'. ${ }^{31}$ Although many patients were identified with migraine in the pill-free interval, few were prepared to enter into a formal clinical trial and usually requested treatment rather than trial medication. This was particularly the case with younger women, and it is notable that the median age of patients entering this study was 33 years. Although recruitment problems had been expected, the difficulties encountered were greater than expected. Consequently, for future trials we will make planning for recruitment part of the overall trial design. As a result of the difficulties we experienced in this study, we have developed an ongoing database in order that we may identify suitable potential subjects who have expressed an interest in participating in clinical research. We would not bother with advertising in the media again as this generated a considerable amount of work and cost as few of the women who telephoned expressing an interest were eligible for the study; most used the opportunity to seek general advice about their headaches. Other researchers have found similar problems when advertising for clinical trial patients with one group reporting that only $10 \%$ of patients interviewed

Table 4 The number of days (0 to 14) with migraine according to whether there was nausea, vomiting or photophobia

\begin{tabular}{|c|c|c|c|c|c|c|c|c|c|}
\hline \multirow[b]{2}{*}{ Patient number } & \multicolumn{3}{|c|}{ With nausea } & \multicolumn{3}{|c|}{ With vomiting } & \multicolumn{3}{|c|}{ With photophobia } \\
\hline & Oestrogen & Placebo & Difference & Oestrogen & Placebo & Difference & Oestrogen & Placebo & Difference \\
\hline 1 & 1 & 0 & 1 & 0 & 0 & 0 & 0 & 0 & 0 \\
\hline 2 & 0 & 0 & 0 & 0 & 0 & 0 & 0 & 0 & 0 \\
\hline 3 & 0 & 0 & 0 & 0 & 0 & 0 & 0 & 0 & 0 \\
\hline 4 & 1 & 1 & 0 & 0 & 0 & 0 & 0 & 0 & 0 \\
\hline 5 & 2 & 1 & 1 & 0 & 0 & 0 & 5 & 8 & -3 \\
\hline 6 & 0 & 3 & -3 & 0 & 2 & -2 & 0 & 2 & -2 \\
\hline 7 & 0 & 0 & 0 & 0 & 0 & 0 & 0 & 0 & 0 \\
\hline 8 & 0 & 0 & 0 & 0 & 0 & 0 & 0 & 0 & 0 \\
\hline 9 & 2 & 1 & 1 & 0 & 0 & 0 & 4 & 5 & -1 \\
\hline 10 & 3 & 0 & 3 & 2 & 0 & 2 & 4 & 0 & 4 \\
\hline 11 & 0 & 0 & 0 & 0 & 0 & 0 & 1 & 1 & 0 \\
\hline 12 & 6 & 4 & 2 & 0 & 0 & 0 & 0 & 0 & 0 \\
\hline 13 & 1 & 1 & 0 & 0 & 0 & 0 & 1 & 0 & 1 \\
\hline
\end{tabular}


in response to an advertisement actually entered the study. ${ }^{32}$ Continuance rates were not reported.

Transdermal patches were used as these provide stable plasma levels of oestrogen. ${ }^{33}$ The $50 \mu \mathrm{g}$ dose was used. Placebo control is an absolute requirement for migraine trials. ${ }^{34}$ This is because the placebo effect in migraine prophylaxis is usually in the range of $20-40 \%$ and in some trials, even higher. A drug should, therefore, be demonstrated to be superior to placebo. The $50 \mu \mathrm{g}$ dose was considered the appropriate dose, since although studies of menstrual migraine had been more successful when higher doses of oestrogen were used. ${ }^{20-22}$ These results could not necessarily be extrapolated to women taking COCs. Women taking COCs are likely to have a high background level of ethinyloestradiol during the pill-free interval and supplementing these levels should be undertaken with some caution.

In hindsight, the dose of oestrogen $(50 \mu \mathrm{g})$ was probably too low. Although this may reflect lack of efficacy of oestrogen supplements, several patients in the present study went on to use $100 \mu \mathrm{g}$ patches during the pill-free interval and reported success. A better trial design would have been to extend the trial for a further two cycles and use combinations of placebo and $50 \mu \mathrm{g}$ patches to achieve pillfree interval supplements of placebo, $50 \mu \mathrm{g}$ patches and $100 \mu \mathrm{g}$ patches, each for two cycles. This would have extended the trial by a further two cycles, which might potentially have been a problem for recruitment. However, the main problem with recruitment was getting women to participate in the first instance; once they were in the trial, continuance was good. Ideally, a $150 \mu \mathrm{g}$ comparative dose would have been useful but would have raised issues of the acceptability of using three patches simultaneously.

Further studies could also compare the efficacy and acceptability of tricycle regimens versus oestrogen supplements in the pill-free interval. Trials of oestrogen supplements could also include oral formulations taken daily during the pill-free interval, as this may be more acceptable to women who are used to taking daily oral contraception.

Trials formally designed to assess the comparative frequency of migraine in women taking COCs containing different progestogens would also be valuable as the results could aid the decision about the choice of COC for women with migraine without aura.

Studies to identify other potential mechanisms of migraine in the pill-free interval are also recommended. Urinary assays of oestrogens and other relevant hormones could be assessed in relation to the occurrence of headache and migraine as oestrogen withdrawal may be only one of several causes.

\section{Conclusion}

Unfortunately, no firm conclusions can be based on the results since no associations were statistically significant. However, the observations that women using $50 \mu \mathrm{g}$ oestrogen supplements tended to have fewer migraines and, if they did occur were less severe, are consistent and biologically plausible given current evidence. The results of this study, taken in combination with results of other studies using oestrogen supplements for menstrual migraine, suggest that a larger, randomised, placebo-controlled trial using at least $100 \mu \mathrm{g}$ patches in the pill-free interval is necessary to clarify and confirm the above observations.

\section{Acknowledgements}

The authors would like to thank Janssen-Cilag for providing active and placebo transdermal oestradiol patches and for providing financial support for the study, Dr Barbara Hollingworth and Dr Anne Szarewski for their invaluable comments, and Laura Mann who was involved in recruitment and in the conduct of the trial.

This study was undertaken as a dissertation for the MFFP awarded by the Faculty of Family Planning and Reproductive Medicine of the Royal College of Obstetricians and Gynaecologists. It was supervised by Dr Barbara Hollingworth.

\section{Statements on funding and competing interests}

Funding. Janssen-Cilag as mentioned in the Acknowledgements section. Competing interests. None declared.$$
\text { R }
$$

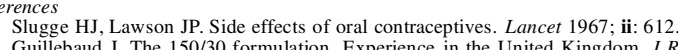
Guillebaud J. The 150/30 formulation. Experience in the United Kingdom. J Rep Med 1983; 28 (Suppl. 1): $66-70$.

years of clinical experience with an oral contraceptive containing 30 Forrog ethinyl-estradiol and 150 microg desogestrel. Contraception 1998; 51: 3 . containing 20 micrograms oestrogen. Contraception 1992; 46: 477-488.

Larsson-Cohn U, Lundberg PO. Headache and treatment with oral contraceptives. Acta Neurol Scand 1970; 46: 267-278

Kudrow L. The relationship of headache frequency to hormone use in migraine. Headach 1975; 15: 37-40.

Ryan RE. A controlled study of the effects of oral contraceptives in migraine. Headache 1978 17: $250-252$

Philips BM. Oral contraceptive drugs and migraine, Br Med J 1968; 2: 99

Whitty CWM, Hockaday JM, Whitty MM. The effect of oral contraceptives on migraine. Lancet 1966; i: 856-9.

and oral contraceptives. Headache 1976; 15: 247-25

1 Horowski R, Runge I. Possible role of gonadal hormones as triggering factors in migraine. Funct Neurol 1986: 1: 405-14.

MacGregor EA. 'Menstrual' migraine: towards a definition. Cephalalgia 1996; 16: 11-21.

Somerville BW. The role of estradiol withdrawal in the etiology of menstrual migraine.

Neurology $1972 \cdot 22 \cdot 355-365$.

14 Somerville BW. Estrogen-withdrawal migraine. 1. Duration of exposure required an 239-244.

15 Epstein MT, Hockaday JM, Hockaday TDR. Migraine and reproductive hormones throughou the menstrual cycle. Lancet 1975;i: 543-548.

6 Lichten E, Lichten J, Whitty A, et al. The confirmation of a biochemical marker for women' hormonal migraine: the depo-octroliol chlenge test. Headache 1996; 36: 367-37।.

Somerville BW. Estrogen-withdrawal migraine II. Attempted prophylaxis by continuous estedicl adis.

M, Mauvais-Jarvis P, et al. Prevention of menstrual migraine by percutaneous oestradiol. Br Med J 1986; 293: 1450

percutaneous estradiol. Gynaecol Endocrinol 1988; 2: 113-120. percutaneous estradiol. Gynaecol Endocrinol 1988; 2: 113-120. Cephalalgia 1993; 13 (Suppl. 13): 244.

21 Pradalier A, Vincent D, Beaulieu Ph, et al. Correlation between oestradiol plasma level and therapeutic effect on menstrual migraine. In: New advances in headache research., Cliffor

22 Rose F (ed.). London: Smith-Gordon, 1994; 129-132. TTSS $^{\circledR}$ and the value of contingent negative variation and exteroceptive temporalis muscle

3 Suppression test. Headache 1994; 34: 103-106.

24 Loudon N, Glasier A, Gebbie A (eds). Handbook of family planning and reproductive health care (3rd edn). Edinburgh: Churchill Livingstone, 1995.

. Influence of contraceptive pill and menstrual cycle on serum lipids and high-density lipoprotein cholesterol concentrations. Br Med J 1982; 284: $1213-215$

26 Tzourio C, Tehindrazanarivelo A, Iglésias S, et al. Case-control study of migraine and risk of ischaemic stroke in young women. Br Med $J 1995$; 310: 830-833.

27 Lidegaard O. Oral contraceptives, pregnancy and the risk of cerebral thromboembolism: the influence of diabetes, hypertension, migraine and previous thrombotic disease. $\mathrm{Br} \mathrm{J}$ Obster

28 Gynaecol 1995; 102: 153-159. Cardiovascular Disease and Steroid Hormone Contraception. Migraine and stroke in young women: case-control study. $B r$ Med J 1999; 318: 13-1

. Henderson BE. Postmenopausal oestrogen treatment and stroke: prospective study. Br Med J 1988; 297: 519-522.

30 Headache Classification Committee of the International Headache Society. Classification and diagnostic criteria for headache disorders, cranial neuralgias and facial pain. Cephalalgia 1998; 8 (Suppl. 7): $1-96$

31 Hamilton M. Computer programmes for the medical man: a solution. $\mathrm{Br}$ Med J 1965; it: $1048-1050$.

32 Lassen LH, Ulrich V, Daugaard D, et al. Recruiting migraine patients to clinical trials by advertisement. In: Headache treatment: trial methodology and new drugs, Olesen J, TfelHansen P (eds). Philadelphia: Lippincott-Raven Publishers, 1997; 99-102.

3 Kuhl H. Pharmacokinetics of oestrogens and progestogens. Maturitas 1990; 12: 171-197. 34 International Headache Society Committee on Clinical Trials in Migraine. Guidelines for 